\title{
REFLEXÕES E CONTRIBUIÇÕES PARA A METODOLOGIA DO ENSINO DE FILOSOFIA NA PERSPECTIVA DA PEDAGOGIA DA AUTONOMIA FREIRIANA.
}

\author{
Junot Cornélio Matos ${ }^{1}$ \\ Adamo Micael Medeiros ${ }^{2}$
}

\section{Resumo}

Este artigo versará sobre algumas reflexões acerca do fenômeno do ensino na visão Freiriana, e sua relação com a metodologia do ensino de Filosofia. Para cumprir tal intento utilizaremos como principal foco de análise o livro de Paulo Freire Pedagogia da Autonomia dialogando com filósofos da tradição e pensadores da filosofia da educação. O objetivo ao escrever esse artigo é tentar fazer uma reflexão filosófica acerca dos saberes necessários à docência, buscando acrescentar algo nessa temática que não passou pelo escopo de reflexões de Paulo Freire.

Palavras-Chave: Ensino, Metodologia, Filosofia, Paulo Freire.

\section{Resumen}

Este artículo propone algunas reflexiones acerca del fenómeno de la enseñanza el na perspectiva freireana y su relación con la metodología del de la enseñanza de la filosofía. Para esto se utilizará como obra principal el libro Pedagogía de la Autonomía de Paulo Freire en diálogo con otros filósofos de la tradición y pensadores de la filosofía de la educación. Con esto, intenta hacer una reflexión filosófica acerca de los saberes necesarios a la docencia, tratando de acrecer algo a esta temática que no ha pasado por la reflexión de Freire.

Palabras clave: Enseñanza, Metodología, Filosofía, Paulo Freire.

\section{Considerações iniciais}

O que é ensinar? A partir dessa primeira indagação surge uma questão de dimensão mais complexa: o que é ensinar filosofia? Para poder responder a questão anterior, é necessário responder mais outra questão, que já foi debatida e defendida com inúmeras definições no decorrer da longa história da filosofia sendo central para a nossa reflexão: o que é a filosofia? Essas questões possuem uma grande importância para a reflexão acerca do ensino da filosofia, no entanto existem questões didáticas gerais que devem ser pensadas por todos os educadores

\footnotetext{
${ }^{1}$ Professor do Departamento de Filosofia da UFPE e do Mestrado em Educação da UFAL. Doutor em Educação pela UNICAMP e Mestre em Filosofia pela UFPE. E-mail: junotcmatos@gmail.com ${ }^{2}$ Graduado em Filosofia pela Universidade Federal de Pernambuco.
}

MATOS, Junot Cornélio; MEDEIROS, Adamo Micael. Reflexões e contribuições para a metodologia do ensino de filosofia na perspectiva da Pedagogia da Autonomia freiriana. Revista Sul-Americana de Filosofia e Educação. Número 24: maioout/2015, p. 121-136. 
que se dedicam seriamente a sua profissão: É possível estabelecer uma relação de ensino se prescindindo dos alunos? É possível uma aula verdadeiramente filosófica em que o professor recuse as indagações dos alunos dentro do escopo do fenômeno do ensino, como se o professor fosse o detentor da sabedoria e os discentes, ignorantes que esperam um pouco da sabedoria do mestre? Quais são as competências necessárias ${ }^{3}$ para a prática docente dos professores de filosofia? $\mathrm{E}$ quais as contribuições que alguns filósofos da tradição e Paulo Freire podem fornecer a essas questões?

Essas são algumas questões que serão abordadas nesse artigo buscando compreender o ensino da filosofia e contribuir de alguma forma para o debate acerca das competências necessárias que os professores de filosofia devem possuir para realizar um ensino mais crítico e reflexivo ${ }^{4}$ fazendo a relação com a reflexão de alguns filósofos e Paulo Freire que pensou detidamente acerca das competências para um ensino mais crítico e humano. Sabemos dos inúmeros problemas enfrentados tanto pela parte dos estudantes de filosofia da escola básica, mais especificamente aqueles que fazem parte da rede pública de ensino que muitas vezes não possuem motivação para estudar (por inúmeros fatores: falta de

\footnotetext{
${ }^{3} \mathrm{O}$ conceito de competências que os docentes precisam despertar nos alunos está atrelado às habilidades, os professores devem buscar desenvolver junto aos seus alunos um conjunto de habilidades em cada disciplina específica que está na escola. Os PCN's nesse sentido buscaram estabelecer as matérias não tanto em vista de trabalhar os conteúdos, mas sim as habilidades que os estudantes precisam desenvolver com o contato das matérias que são lecionadas na sala de aula. A filosofia deve desenvolver em seus alunos algumas competências de caráter geral como é prescrito no PCN, no entanto com uma ênfase maior na capacidade crítica e na autonomia do estudante. Acerca do conceito de competências podemos compreender que "Competência é compreendida como uma capacidade de agir eficazmente em um determinado tipo de situação, apoiada em conhecimentos, mas sem se limitar a eles. Tratar-se-ia de uma capacidade de resposta que ultrapassa a mera repetição, mas, ao mesmo tempo, apóia-se em conhecimentos prévios. Entretanto, a noção de competência é sempre interior a cada disciplina, não havendo noção universal. Sendo da ordem das disposições, só pode ser lida e reconhecida à luz das matrizes conceituais específicas. Em certos casos, a competência se mostra na elaboração de hipóteses, visando à solução de problemas. Em outros casos, porém, uma vez que competências não se desenvolvem sem conteúdos nem sem o apoio da tradição, a competência pode significar a recusa de soluções aparentes por recurso ao aprofundamento sistemático dos problemas" (CARLOS; SOUZA; EDMILSON, 2012, p.383)

${ }^{4}$ A reflexão realizada acerca do ensino e das competências implica principalmente sobre os professores de filosofia, não obstante a filosofia da educação e o ensino de filosofia podem contribuir para esclarecer uma melhor forma de ensino e de abordagem dos conteúdos em todas as disciplinas da escola. Sabemos que as primeiras escolas (Platônica, Aristotélica, epicurista, estoica) foram estabelecidas pelos filósofos gregos e o processo de aprendizagem foi pensada por inúmeros filósofos.
} 
motivação dos pais, ambiente familiar problemático, pobreza, violência e inúmeros outros que infelizmente fazem parte de nossa sociedade). Junto a esses problemas soma-se o da parte dos professores que não se sentem motivados seja pela infraestrutura da escola, baixos salários, número de aulas excessivas (uma vez que os professores de filosofia muitas vezes são de outras disciplinas como história e daí precisam lecionar filosofia e sociologia para cumprir a carga horária). A reflexão que esse artigo busca suscitar é contribuir para além desses problemas vigentes e pensar algumas formas de ajudar os professores de filosofia em sua prática diária apesar de todas as dificuldades e ainda mais em fazer a transposição de um simples texto acadêmico para a realidade do dia a dia nas salas de aula de filosofia. Dessa forma faz-se necessário compreender um pouco de como foi pensado a educação no nosso passado e buscar uma forma de pensar o ensino de filosofia que por ser uma disciplina recente a ser incluída no currículo da escola básica, não possui uma tradição concernente a sua metodologia e ensino como o são outras disciplinas como a matemática e a biologia, não obstante grande é o esforço de pesquisadores do ensino da filosofia para melhorar a prática docente.

\section{Relações entre autonomia e o ensino de filosofia}

Como já está muito debatido as escolas, e, dentro do âmbito das instituições de ensino como um todo, concebem o ensino baseado na mera exposição de conteúdos visando a memorização para serem posteriormente cobrados na avaliação. Dessa forma o fenômeno do ensino era pensado como um processo mecânico: Exposição, repetição, memorização, avaliação. Essa concepção de ensino baseado na mera exposição com o objetivo de memorização é denominado por Paulo Freire como concepção bancaria do processo do ensino.

A prática docente em sala de aula estão norteadas fundamentalmente a partir do que ele entende por ensino ${ }^{5}$. Um professor que deseja apenas transferir

\footnotetext{
${ }^{5}$ De acordo com Paul H. Hirst, é de vital importância para um professor dentro da atividade pedagógica se ter uma clara noção da atividade em que se esta envolvido "Clarificar o conceito de ensino é de importância vital porque o modo como os professores entendem o que é ensinar afeta grandemente o que efetivamente fazem na sala de aula. Se, é verdade que as nossas atividades dependem do modo como as vemos, das nossas crenças acerca delas, então, se tivermos ideias estranhas e esquisitas sobre o que é ensinar, será provável que, sob esse nome, façamos coisas
} 
conteúdos, sem levar em conta os conhecimentos prévios que os alunos possam ter, está trabalhando metodologicamente de forma muito equivocado uma vez que o estudante é o principal ator no processo ensino-aprendizagem. Assim, todos os esforços devem ser voltados para o aprendizado dos alunos. O docente deveria atentar para os conteúdos prévios que os discentes possuem. Uma simples sondagem feita pelo professor pode ser de grande ajuda para saber o modo como os alunos compreendem o assunto que será abordado. O que não poderá ocorrer se o professor não assumir uma postura dialógica em sua prática docente, enfatizando em seu trabalho pedagógico, exclusivamente, a atividade do ensino. A metodologia empregada por Sócrates para ensinar a atividade do filosofar consistia no ideal de autonomia pensado por Paulo Freire e que é descrito como um dos objetivos centrais que deve ser alcançado através do ensino da filosofia no ensino médio pelos documentos oficiais que regulam o ensino de filosofia no País. Esse ideal se resume na capacidade do professor poder fazer com que os discentes possam começar a pensar por si mesmos, estimulando-os através de perguntas em uma aula pautada pela dialogicidade.

Para Sócrates pouco progresso mental se obtinha do simples fato de ministrar conhecimentos com os métodos populares que os sofistas proporcionavam - que almejavam disseminar informações por meio de prestações formais - uma vez que o método de conversação socrática trazia mais benefícios de aprendizagem, e tinha como objectivo o poder de pensar. O seu alvo era formar jovens capazes de tirar conclusões corretas, e formular a verdade por si mesmos, em vez de dar-lhes conclusões já elaboradas. Portanto, para Sócrates, a educação tinha por objetivo imediato o desenvolvimento da capacidade de pensar, não apenas ministrar conhecimentos. (FERNANDO, p.2).

Nesse sentido o modo de filosofar socrático torna-se um modelo paradigmático para os professores de filosofia por darem a possibilidade de fazer com que os alunos aprendam de forma significativa, se apropriando verdadeiramente do conteúdo através de um esforço reflexivo de si mesmos e não apenas decorando conceitos que no mais das vezes são esquecidos ao término daquele ano. Os professores bancários são os sofistas contemporâneos na medida em que não se importam com o real aprendizado dos alunos, mas estão apenas

estranhas e esquisitas. Um dos requisitos mais importantes para um professor é seguramente ter uma noção clara da natureza da atividade central em está profissionalmente envolvido" (HIRST, 1973, p. 66) 
preocupados em ministrar os conteúdos, sem problematizar as questões em vista de que os alunos ousem pensar por si mesmos e possam filosofar.

Uma vez que "ensinar inexiste sem aprender" um ensino em que meramente se baseia em transmitir conteúdos, sem levar em consideração as possíveis considerações dos discentes como pontos de vista ou possíveis questionamentos sobre o que foi ensinado termina por acarretar, ao meu modo de pensar, em uma mutilação do espírito inquiridor que é de certa maneira uma das principais características do espírito filosófico, uma vez que a filosofia consiste em uma constante interrogação acerca do que nos é posto, buscando saber as causas e fundamentações do que é transmitido diferentemente de todas as outras matérias que existem no ensino médio, portanto possuindo uma especificidade única.

\begin{abstract}
O ensino de filosofia distingue-se de qualquer outro tipo de ensino, pois é um ensino filosófico. Exige da parte do professor a consciência da atitude filosófica. Em vez de conteúdos expresso em doutrinas, teorias e sistemas consignados nas histórias da filosofia, o "objeto" da ensinabilidade e da apropriação é uma atitude" ( Von Zuben, p.8))

Educador e educandos se arquivam na medida em que, nesta destorcida visão da educação, não há criatividade, não há transformação, não há saber. Só existe saber na invenção, na reinvenção, na busca inquieta, impaciente, permanente, que os homens fazem no mundo (Freire, 1998, p. 66)
\end{abstract}

Esse professor que apenas reproduz os conteúdos está longe de se tornar um docente que ensina filosofia stricto sensos, já que ele estaria longe de fazer com que os discentes pensassem de maneira correta ${ }^{6}$. E um professor de filosofia deve dar prioridade a esse desafiar os seus alunos para uma reflexão mais substancial dos conteúdos que são ministrados, vale-se ressaltar que não apenas os professores de filosofia, mas os professores de uma forma geral independentemente de qual seja a disciplina, não apenas em relação a filosofia. O professor que se queria fazer valer de seu nome deve levar em consideração não apenas o que transmitir, mas, para quem está dirigindo, deve levar em consideração a situação social, econômica, epistemológica, psicológica de seus alunos. Um ensino que se faz sem

\footnotetext{
${ }^{6}$ A partir da concepção Freiriana de ensino, os professores que resumissem a filosofia apenas aos seus conteúdos de forma monológica, sem problematiza-los e criticizá-los, terminariam por descaracterizar o próprio ensino e, por conseguinte, a filosofia. "Daí a impossibilidade de vir a tornar-se um professor crítico se, mecanicamente memorizador, é muito mais um repetidor cadenciado de frases e de idéias inertes do que um desafiador" (FREIRE, 1998, p.56)
} 
ter uma base das condições prévias do aluno, inviabiliza uma relação pedagógica em que a "dodiscência" se faz presente, por vezes, as aulas terminam por se transformar em monólogos verbalistas que domesticam a capacidade crítica $e$ eminentemente filosófica que porventura venha a ocorrer nos alunos no ambiente da sala de aula que em sua essência deveria ser o local em que a curiosidade teria de ser despertada para favorecer uma aprendizagem mais efetiva.

Não é possível respeito aos educandos, à sua dignidade, a seu ser formando-se, à sua identidade fazendo-se, se não se levam em consideração as condições em que eles vêm existindo, se não se reconhece a importância dos "conhecimentos de experiência feitos" com que chegam à escola (FREIRE, 1998, p.64)

No primeiro contato, em uma aula de Filosofia, possivelmente os alunos se perguntarão, afinal de contas o que é a filosofia? O professor que responder essa questão filosófica recorrendo a algumas das respostas que foram dadas durante o curso da história da filosofia ou recorrendo a definição etimológica terminaria por ofuscar uma questão que é especificamente filosófica. Essa indagação - Que é filosofia? - "constitui um tema próprio e fundamental da filosofia mesma, e não admite, de modo algum, uma resposta única" (CERLETTI, 2009, p.14). Por isso se faz de extrema importância a relação entre o professor que se faz atuante na sala de aula e os discentes, pois, se esse, responder a questão de modo bancário e conteudista destrói a intencionalidade ${ }^{7}$ da pergunta filosófica, $e$ transforma a essência mesma da filosofia em uma mera transmissão de conhecimento, fazendo fenecer a curiosidade do docente e consequentemente do discente "A curiosidade que silencia a outra se nega a si mesma também" (FREIRE, 1998, p. 85) .

Ao questionar os alunos sobre o que é a filosofia? O professor conteudista, vai esperar uma única resposta, muito provavelmente a que ele tem em mente, e,

\footnotetext{
${ }^{7} \mathrm{O}$ conceito de intencionalidade foi abordado de maneira mais detida por Cerlet, para esse uma pergunta não é filosófica em si. A especificidade filosófica de uma pergunta estaria ligada intrinsicamente pela intencionalidade do formulador da questão nesse caso o professor de filosofia, já que uma mesma pergunta pode ter diversos horizontes de sentido, a pergunta "o que é a vida?" , pode ser pensada nas diversas instâncias, senso comum, científico, religioso e filosófico " O que faz com que uma interrogação possa ser considerada filosófica, fundamentalmente está mais na intencionalidade de quem pergunta, ou se pergunta, do que na pergunta em si" (CERLETTI, 2009, p.23)
} 
qualquer outra formulação que não seja a esperada por ele, vai ser considerada como uma resposta equivocada, para não dizer errônea dos alunos, fazendo com que a filosofia perca a sua essência questionadora como também que os discentes permaneçam em sua menoridade $e^{8}$ não possam ousar pensar por si próprio $e$ transforme os estudantes mais em autômatos do que autônomos em um ensino que descarta a reflexão e, faz dos alunos meros recipientes e tábulas rasas.

Utilizamos esse exemplo da pergunta sobre o que é a filosofia, por acreditarmos que essa seja uma das primeiras questões que a maioria dos professores terão que lidar em sua primeira aula no ensino médio de filosofia, uma vez que muitos discentes nunca tiveram contato com essa "disciplina", e quando a tiveram ocorreu de forma simplista e deturpada. Porém, muitos professores ministram suas aulas no ensino médio como se a filosofia fosse apenas um minicurso da história da filosofia ${ }^{9}$, fazendo da filosofia uma simples exposição dos pensamentos e teses dos filósofos da tradição: Sócrates, Platão, Aristóteles, Agostinho, Descartes, Kant, Hegel...... Até os filósofos de nossa contemporaneidade. O professor do ensino médio sempre terá que realizar determinados recortes dentro do grande número de pensadores que existe na tradição filosófica, pois, parece uma tarefa impossivel ministrar 2500 anos de história da filosofia no curto espaço de tempo que é concedida a filosofia no ensino

\footnotetext{
${ }^{8} \mathrm{O}$ conceito de menoridade foi utilizado por Kant para designar as pessoas que não se guiavam pela sua própria razão, em contraposição a maioridade que seria o ideal da Aufklärung no projeto da filosofia moderna iluminista, não obstante, penso a definição de maioridade utilizada por Kant como o objetivo primeiro que deve ser buscado pelos professores de filosofia para despertar uma postura pelos educandos no processo pedagógico "A menoridade é a incapacidade de se servir do entendimento sem a orientação de outrem. Tal menoridade é por culpa própria, se a sua causa não residir na carência de entendimento, mas na falta de decisão e de coragem em se servir de si mesmo, sem a guia de outrem. Sapere aude! Tem a coragem de te servires do teu próprio entendimento!" (KANT, 2005, p.13)

9 Talvez não exista nenhum problema para um professor que assuma sua posição Hegeliana enquanto busca utilizar como método para as suas aulas de filosofia uma abordagem em cima dos conteúdos da história da filosofia, uma vez que para Hegel "A história da filosofia é a filosofia" (HEGEL, 1986, p. 57). Contudo, na visão de Carlos Eduardo Vieira essa concepção da filosofia não implica necessariamente no abandono do pensamento autônomo "Esta concepção, exposta por Hegel em textos particularmente voltados para esse fim, colocou a história no centro do debate filosófico, na medida em que esta opção não significou o abandono do caráter edificante da filosofia. Em termos propriamente hegelianos, o conhecimento histórico da filosofia propicia pensar a evolução e o desenvolvimento do espírito no tempo e, sobretudo, operar a síntese racional que articula os resultados atingidos pela objetivação da razão na história. O olhar para o passado não significa distanciar-se dos projetos filosóficos em disputa no presente" (VIEIRA, 2009, p. 7).
} 
básico ou algo que o valha, por isso se faz necessário utilizar o Princípio de separação "Não é necessário saber de tudo, e tudo saber, para ser saber apropriável deve poder ser limitado" (GALLO; KOHAN, 2000, p.98). Kant havia pensado esse mesmo princípio há muitos séculos atrás ao afirmar que é preferível aprender pouco, no entanto esse pouco conteúdo que foi apreendido o seja com propriedade. Alguns professores em sua prática pedagógica erroneamente priorizam em estudar um grande número de conteúdos de forma rápida $e$ superficial, isso termina acarretando com que não ocorra um aprendizado efetivo "Vale mais saber pouco, mas sabê-lo bem, que saber muito, superficialmente" (KANT, 1996, p.93).

A entrada da filosofia no currículo das escolas depois de mais de quarenta anos de ocultamento traz consigo questões e problemáticas que nós, filósofos da educação temos que nos colocar. Qual a importância da entrada da filosofia nas escolas? Quais os seus objetivos? Qual a especificidade dos conteúdos?

Primeiramente a filosofia ressurge nas escolas como um meio e não como um fim em si mesma. Durante grande parte da tradição, a filosofia era vista como um fim em si mesma, como algo que não possuía nenhuma utilidade extrínseca a sua atividade, atividade essa que consistia em se filosofar. Porém, ao ser incorporado como uma disciplina dentro das instituições de ensino, a filosofia perde essa clássica visão de fim em si mesma para tornar-se instrumento, um meio para se alcançar algo.

A filosofia é incorporada nas escolas do ensino médio no intuito de suscitar nos educandos habilidades que despertem uma disposição para a cidadania, eticidade, autonomia e o pensamento crítico. Essas competências devem ser buscadas de acordo com os parâmetros curriculares nacionais no que concerne a disciplina de filosofia, disciplina essa que terminou por se tornar um meio.

No Artigo $N^{\circ} 35$ da LDB, destacam-se as competências e habilidades a serem trabalhadas por parte dos professores com os discentes durante o processo de ensino, mais especificamente sobre o ensino de filosofia:

a) "A consolidação e o aprofundamento dos conhecimentos adquiridos no ensino fundamental, possibilitando o prosseguimento de estudos" (inciso I) 
b) "A preparação básica para o trabalho e a cidadania do educando, para continuar aprendendo" (inciso II)

c) "O aprimoramento do educando, incluindo a formação ética e o desenvolvimento da autonomia intelectual e do pensamento crítico" (inciso III) ( Grifo meu)

Esses indicadores das incumbências dos professores de filosofia ao ministrarem aulas de filosofia ressaltam o caráter reflexivo que deve ser trabalhado nas salas de aula, e não somente ele, como também impulsionar a eticidade dentro das escolas. A ética é uma das diversas partes que integram o corpo disciplinar da filosofia, nenhuma outra disciplina da escola básica tem por objeto de estudo a ética especificadamente, não obstante, as outras disciplinas da escola básica podem e devem trabalhar a ética dentro dos seus respectivos conteúdos, como a história, biologia, química, sociologia, física, e as outras matérias, não com tanta profundidade como é a ética trabalhada numa perspectiva filosófica.

Caso algumas dessas matérias sejam ministradas de maneira conteudista, dificilmente o professor vai conseguir trabalhar a ética na perspectiva dessa mesma matéria, trabalhar a ética exige uma sensibilidade e uma criatividade para poder relacioná-los interdisciplinarmente, já que a ética é uma parte da filosofia e não pode ser trabalhada apenas realizando uma abordagem dos conteúdos de forma repetitiva e massiva buscando a memorização dos alunos, mas sim fazer com que os alunos compreendam o significado efetivo e possam utilizar esses conhecimentos em sua vida prática, nas relações com as outras pessoas e com eles mesmos. Para Paulo Freire a ética é essencial para que os discentes possam ascender à uma maior autonomia e criticidade e possam sair da esfera em que não passam de alunos que apenas escutam o que o professor tem a dizer com o objetivo de memorizar "A necessária promoção da ingenuidade a criticidade não pode ou não deve ser feita a distância de uma rigorosa formação ética" ( FREIRE, 1996, p.19) Nesse sentido a filosofia tem uma vital importância em nossas escolas básicas uma vez que pode possibilitar uma formação mais humana e ética $e$ propiciar a possibilidade de fazer com que os estudantes se tornem pessoas mais cidadãs e reflexivas.

A filosofia chega à educação básica com a finalidade de transformar a realidade social em que estamos situados, ela tem como uma das competências 
desenvolver a autonomia e o pensamento crítico dos alunos. Todas as matérias, na medida do possível, deveriam trabalhar essas referidas competências, e transformar as perspectivas dos discentes mostrando-lhes a possibilidade de um uso mais autêntico do pensamento humano na construção e reconstrução do conhecimento. Mas, nem todos os profissionais da educação compartilham essa visão, fazendo da educação, repetição. E essas competências tem um lugar especial dentro do ensino da filosofia, uma vez que é uma disciplina essencialmente reflexiva $e$ questionadora. Contudo, como é possível estimular essas disposições?

\section{Pensando uma metodologia filosófica da autonomia}

É possível que um professor possa se manter neutro de sua posição filosófica no ensino da filosofia? Existe uma maneira única de ensinar a filosofia? Uma receita pronta que remediaria todos os problemas enfrentados pelos docentes de filosofia em sala da aula? Em suma, é possível uma metodologia na prática do ensino de filosofia que desperte nos alunos uma atitude crítica em relação ao mundo e faça deles pessoas mais autônomas?

De acordo com pedagogos e filósofos é pouco provável a possibilidade do docente de se manter em um patamar de neutralidade quando se lida com os conteúdos de filosofia, uma vez que o professor que chega à sala de aula, em sua formação acadêmica ${ }^{10}$ adquiriu uma concepção do que é a filosofia, e isso se fara

\footnotetext{
${ }^{10}$ Levando em consideração que esse docente obtive a licenciatura em filosofia, o que infelizmente não acontece muitas vezes na nossa realidade educacional uma vez que inúmeros professores assumem a incumbência de ministrar as aulas de filosofia, sem dominar os conteúdos específicos da disciplina e sem refletir sobre as implicações que pode ocorrer para a imagem da filosofia, em minha concepção a já tão negativa imagem da filosofia termina por ser caricaturada de forma muito mais nefasta fazendo com que os alunos terminem o ensino médio com a impressão de que as aulas de filosofia eram simples viagens do professor ou que as aulas eram meras discussões sem nenhuma importância, ou quando muito a filosofia era apenas para entender o que aqueles velhos mortos haviam pensado, sem nenhuma relação com as suas vidas. Portanto faz-se necessário que essa realidade em que professores de outras áreas assumam a aula de filosofia deve ser pensado com mais seriedade por parte das escolas que muitas vezes preferem racionalizar recursos em detrimento da formação dos alunos "É oportuno recomendar que não se pode de nenhum modo dispensar a presença de um profissional da área, qualquer que seja a forma assumida pela escola para proporcionar a construção de competências de leitura e análise filosófica dos diversos textos de modo significativo. Nesse sentido, cabe frisar que o conhecimento filosófico é um saber altamente especializado e que, portanto, não pode ser adequadamente tratado por leigos." (Parâmetros Curriculares Nacionais- Ensino Médio, p. 342)
} 
visível em sua prática docente e no modo de lidar com os conteúdos. Vale ressaltar um trecho presente no $\mathrm{PCN}$ de filosofia em que se fala sobre a impossibilidade de uma completa assepsia sobre os pressupostos teóricos dos professores no ensino da filosofia, bem como nos prejuízos que pode acarretar para o profissional que não assuma a sua identidade filosófica diante das circunstâncias de ensino dentro da ambiência da filosofia na sala de aula:

Em suma, a resposta que cada professor de Filosofia do Ensino Médio dá à pergunta que Filosofia? decorre, naturalmente, da opção por um modo determinado de filosofar que ele considera justificado. Aliás, é fundamental para esta proposta que ele tenha feito sua escolha categorial e axiológica, a partir da qual lê e entende o mundo, pensa e ensina. Caso contrário, além de esvaziar sua credibilidade como professor de Filosofia, faltar-lhe-á um padrão, um fundamento, a partir do qual possa encetar qualquer esboço de crítica. Por certo, há filosofias mais ou menos críticas. No entanto, independentemente da posição que tome (pressupondo que se responsabilize teórica e praticamente por ela), ele só pode pretender ver bons frutos de seu trabalho docente na justa medida do rigor com que operar a partir de sua escolha filosófica - um rigor que, certamente, varia de acordo com o grau de formação cultural de cada um. (PCN. P.48)

Que filosofia é dada em sala de aula? A resposta sobre o que é a filosofia se faz emergente na concepção que temos da ensinabilidade da filosofia, pois, o que se ensina? Esse ensino sempre vai partir de uma concepção prévia do que é a filosofia, refletindo nos conteúdos e principalmente, na metodologia que é utilizada pelo docente.

Pelo o que foi exposto anteriormente se faz necessário pensarmos uma metodologia ${ }^{11}$, própria para o ensino de filosofia, no qual o que esteja em conformidade com o como.

O professor que simplesmente monopoliza o discurso com ares de sábio, banaliza e deforma a essência mesma da filosofia e consequentemente a do ser

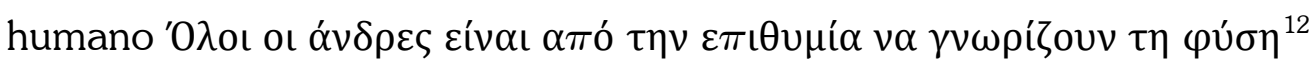

11 Utilizamos o termo metodologia não em um sentido forte, como um corpo de técnicas rigidamente estabelecidos que garantiriam uma indefectibilidade no ensino da filosofia, utilizamos esse termo como uma maneira estratégica de se abordar os conteúdos de filosofia de um modo filosófico que contribua para a autonomia do pensamento crítico dos discentes "Trata-se de uma perspectiva para o trabalho e não um modelo que venha a tornar-se camisa-de-força" ( MATOS, 2000, p.214)

12 Uma das primeiras constatações de Aristóteles em sua metafísica é observar a natureza eminentemente inquiridora dos seres humanos ao dizer que "Todos os homens têm, por natureza, desejo de conhecer". 
A curiosidade como inquietação indagadora, como inclinação ao desvelamento de algo, como pergunta verbalizada ou não, como procura do esclarecimento, como sinal de atenção que sugere alerta faz parte integrante do fenômeno vital (FREIRE, 1996, p.32).

A filosofia que em sua gênese, dialógica, se preocupou com o debate e fundamentalmente com a argumentação, procurando desvelar as falsas aparências no intuito de encontrar o conhecimento, combatendo a atitude dogmática em que os pressupostos eram tidos como intocáveis, mas sim, tendo como eixo norteador a discussão e o compromisso com o debate entre os que se propunham encontrar as soluções dos problemas que eram colocados.

A partir do clássico adágio kantinano "Não se ensina filosofia, ensina-se a filosofar" (KANT, 1998, p.24) surge uma questão sobre o método ou forma de ministrar aulas de filosofia, É possível fazer dos alunos do ensino médio, futuros filósofos? Fazê-los seres pensantes que se põe e propõe questões filosóficas?

Paulo Freire pensa a relação do ensino, independentemente da disciplina em uma relação "dodiscente" em que os discentes devem se apropriar dos conteúdos, e não apenas recebe-los sem nenhuma reflexão sobre o que se é transmitido. Essa atitude filosófica, crítica e indagadora pode e deve ser muito explorada pela filosofia, uma vez que essa atitude inquiridora está incluída na própria definição etimológica dessa disciplina, em que se busca a sofia, pois ainda não a possui de forma efetiva, assumindo dessa forma um compromisso com o conhecimento partindo do pressuposto que é preciso um esforço indagador para alcançá-lo uma vez que reconhecemos a nossa ignorância. Nesse sentido os professores de filosofia devem fazer para que os discentes aspirem sair da doxa em direção à epistemé, fazendo com que os alunos possam evoluir de sua curiosidade ingênua para uma curiosidade epistemológica. Esse deve ser um dos pressupostos da atitude dos docentes em sua forma de ministrar as aulas e deve ser uma das competências de qualquer professor, não obstante, no campo do ensino da filosofia essa situação se torna muito mais peremptória. Fazer com que os alunos se apropriem do que é aprendido em vez de uma mera atividade memorizadora é uma tarefa em que todo professor deve se incumbir de realizar "O educador não pode negar-se o dever de, na sua prática docente, reforçar a capacidade crítica do educando, sua curiosidade, sua insubmissão" (FREIRE, 1996, p26). 
Desse modo Paulo Freire visa como papel essencial da educação a proposta de fazer os alunos livres, curiosos, insubmissos. Kant em sua forma de conceber a educação pensa que um dos objetivos principais do ensino é libertar os discentes de preconceitos para que possam progredir em sua formação intelectual e cultural "A educação prática ou moral (chama-se prático tudo que se refere á liberdade) é aquela que diz respeito à construção (cultura) do homem, para que ele possa viver como um ser livre." (KANT, 1996, p. 34) Nesse sentido Kant estabelece como objetivo principal da educação a formação dos estudantes para que eles possam exercer a sua liberdade e sejam autônomos para que não fiquem submetidos ao julgo de outras pessoas como os professores para a construção de suas ideias e de sua formação cultural. O que infelizmente ocorre em alguns casos é que os docentes muitas vezes ao invés de promoverem um ensino para que os alunos pensem por si, promovem aulas em que os alunos ficam acorrentados ao que outras pessoas disseram, fazendo com que a tarefa filosófica perca o seu significado "ensinar exige liberdade" liberdade que faça com que os discentes exercitem a sua capacidade de pensarem por si fazendo com que eles assumam uma atitude filosófica, refletindo acerca do que é dito e podendo expressar as suas opiniões na sala de aula, possibilitando o diálogo.

A capacidade de problematização sobre o ensino de filosofia é uma das competências essenciais que um professor de filosofia pode utilizar para despertar o desejo dos alunos rumo a uma tentativa de elaboração de uma resposta, estimulando dessa forma, o pensamento crítico do aluno. A filosofia não surgiu do nada como uma simples abstração ou devaneio desvinculado da realidade vigente dos primeiros pensadores, ela nasceu a partir de problemas concretos que foram constatados pelos filósofos e que se esforçaram tentando responder essas mesmas questões a luz de seu tempo. Desse modo os professores podem incitar os seus alunos na medida em que conseguem fazer em sua prática docente com que um determinado conteúdo de filosofia apresente-se como um problema que pode e deve ser pensado pelos alunos, fazendo com que eles se sintam inquietos $e$ busquem dar algum tipo de solução, estimulando assim uma reflexão crítica e a capacidade do filosofar por parte dos educandos. 
Algo que não pode acontecer na prática pedagógica é a simples transmissão da problemática sem problematizá-la a partir do contexto dos alunos. A pergunta sobre o que é a justiça, pode ser abordada utilizando elementos da vida concreta dos educandos "Por que não discutir com os alunos a realidade concreta a que se deva associar a disciplina cujo conteúdo se ensina? Por que não estabelecer uma "intimidade" entre os saberes curriculares fundamentais e a experiência social que eles têm como indivíduos?” (FREIRE,1996 .30). Com esse tipo de ensino de filosofia vinculada à realidade das vivências dos discentes eles poderão sentir uma inquietação diante do problema que lhes é posto, promovendo uma reflexão no que diz respeito a sua vida mesma, despertando a consciência deles para a tomada de consciência de que os seus pensamentos não estão engavetados como algo sem importância, mas sim, como uma peça integrante do quebra-cabeça das possíveis soluções.

\section{Considerações Finais}

Um ensino filosófico baseado na mera exposição de conteúdos, desvinculados com a realidade dos discentes, longe de fazer um ensino que promova a autonomia e a criticidade ${ }^{13}$ dos estudantes, termina por transformar a aula em algo entediante e distanciado do real significado que uma aula de filosofia deveria ter na sala de aula. Longe de despertar o interesse e atenção dos alunos, rebaixa uma atividade reflexiva em algo meramente mecanicista.

A pedagogia da autonomia contém uma lista das competências necessárias na prática docente para que essa possa despertar a autonomia dos alunos, habilidades essas pensadas para que possibilitem a tomada de consciência por parte dos discentes em qualquer disciplina que seja ministrada nas escolas, no entanto elencamos e estabelecemos uma relação com as habilidades que devem ser desenvolvidas pelos professores de filosofia. A partir do que foi abordado ao longo deste artigo, acreditamos que a reflexão Freiriana juntamente com suas

\footnotetext{
${ }^{13}$ Essas duas características devem ser trabalhadas detidamente através da filosofia e nesse sentido buscamos ao longo do artigo ressaltar que as outras disciplinas podem trabalhar essas competências, no entanto a filosofia possui uma especificidade quanto à isso, uma vez que ela vai para o ensino médio com o objetivo de despertar essas habilidades nos alunos. Portanto o modo como a filosofia vai ser ensinada é tão importante quanto os conteúdos que serão abordados para promover uma maior autonomia dos alunos.
} 
conexões com alguns filósofos da tradição contém inúmeras relações $e$ contribuições com o ensino da filosofia e com a postura que foi assumida por alguns filósofos ao longo da tradição filosófica. Por isso, a reflexão de Paulo Freire possui uma grande contribuição para a metodologia do ensino de filosofia embora ele não tenha se detido de forma especifica no ensino de filosofia, propiciando referenciais teóricos que possibilitam uma prática educacional mais reflexiva $e$ crítica no concernente às aulas de filosofia.

Este artigo não esgota ou a discussão acerca das competências que os professores precisam desenvolver conjuntamente com seus alunos, mas apenas traz alguma luz para o debate atual que emerge ao pensarmos a situação da filosofia atual no ensino médio e como ela vem sendo trabalhada pelos professores para buscar uma melhor forma de abordar metodologicamente os conteúdos no intuito de fazer os alunos pessoas mais críticas e reflexivas, além de despertar o interesse para a filosofia.

\section{REFERÊNCIAS}

ARISTÓTELES, In: Metafísica. REALE, Giovanni (org). Tradução: Marcelo Perine. São Paulo: Loyola, 2002.

BRASIL. Secretaria de Educação Fundamental. Parâmetros Curriculares Nacionais. Brasilia: MEC/SEF.

CERLETTI, A. O Ensino de Filosofia como problema filosófico. Belo Horizonte/MG: Autêntica Editora. 2009.

JOÃO, Carlos; SOUZA, Telma; EDMILSON, Antonio. Conteúdo Básico Comum Filosofia - Ensino médio. 2012. Disponível em: http://portal.mec.gov.br/seb/arquivos/pdf/14Filosofia.pdf.

FERNANDO, Luis. Sócrates: o mestre grego e seu sistema pedagógico refletindo na educação contemporânea. Uberlândia: Faculdade católica de Uberlândia,

FREIRE, Paulo. Pedagogia da Autonomia. Saberes necessários à prática educacional. Rio de janeiro: Paz e terra, 1996.

. Pedagogia do oprimido. Rio de Janeiro: Paz e terra, 1998.

GALLO, Sílvio \& KOHAN, Walter (Orgs.). Filosofia no Ensino Médio. Petrópolis: Vozes, Vol. VI, 2000. 
HEGEL, Georg Wilhelm Friedrich. Introdução à História da Filosofia. Rio de Janeiro: Tecnoprint, 1986.

KANT, Imamnuel. Resposta a pergunta: Que é iluminismo? Textos Seletos. Tradução Floriano de Sousa Fernandes. 3 ed. Editora Vozes: Petrópolis, RJ. 2005.

UNIMEP, 1996.

. Sobre a Pedagogia. Trad. de Francisco C. Fontanella. São Paulo: Editora

LDB - Leis de Diretrizes e Bases da Educação Nacional. LEI No. 9.394, de 20 de dezembro de 1996. D.O. U. de 23 de dezembro de 1996.

MATOS, Junot Cornélio. Em toda parte e em nenhum lugar: A Formação Pedagógica do Professor de Filosofia. Recife: Fasa Ed., 2000.

PAUL, H. Hirst. What is Teaching. Journal of Curriculum Studies, Vol. 3, No 1 (1971), pp. 5-18, reimpresso in R.S. Peters (edr.), The Philosophy of Education, London: Oxford University Press, 1973, pp. 163-177.

VIEIRA, Carlos Eduardo. História da Educação e História da Filosofia: culturas cruzadas a partir das concepções de história e de escrita da história em Hegel. ProPosições vol.20 no.1 Campinas. Jan./Apr. 2009.

VON ZUBEN, Newton A. Filosofia e educação: atitude filosófica e a questão da apropriação do filosofar. In: Pro-posições. Vol 3, nº 2(8), julho, p. 7-27.

MENDES, Ademir Aparecido Pinhelli. Ironia e Maiêutica. In: Filosofia Ensino Médio. Vários autores. Curitiba: SEED-PR, 2006. 